
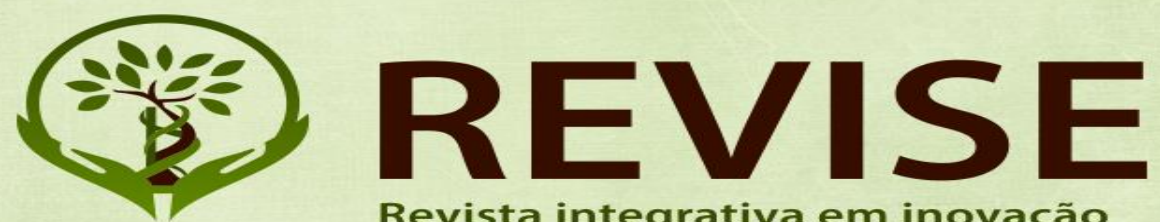

Revista integrativa em inovação tecnológica nas ciências da saúde

ISSN: $2179-6572$

\title{
Conferência: HIDROTERAPIA UMA EXPERIÊNCIA DA FISIOTERAPIA AQUÁTICA
}

Jaqueline Tosta de Almada Santana

FACEMP

\begin{abstract}
RESUMO
$\mathrm{O}$ artigo registra as conferências do evento congresso internacional de inovação tecnológica nas ciências da saúde: a sustentabilidade das práticas integrativas a agroecologia, mais especificamente a conferência Hidroterapia uma experiência da fisioterapia aquática. O evento aconteceu de 15 a 18 de novembro de 2017 no IFBA SAJ sob a direção da Universidade Federal do Recôncavo da Bahia.
\end{abstract}

Palavras-Chave: Hidroterapia. Termalismo. Águas termais. Água mineral. PICS. Fisioterapia. Terapia aquática

\begin{abstract}
The article records the conferences of the event international congress on technological innovation in health sciences: the sustainability of integrative practices in agroecology, more specifically the conference Hydrotherapy an experience of aquatic physiotherapy. The event took place from November 15 to 18, 2017 at IFBA SAJ under the direction of the Federal University of Recôncavo da Bahia.
\end{abstract}

Keywords: Hydrotherapy. Thermalism. Thermal waters. Mineral water. PICS. Physiotherapy. Aquatic therapy

Hidroterapia. Revista Revise, vol 3, $n^{\circ}$ Fluxo Contínuo, p.87 a 98. 

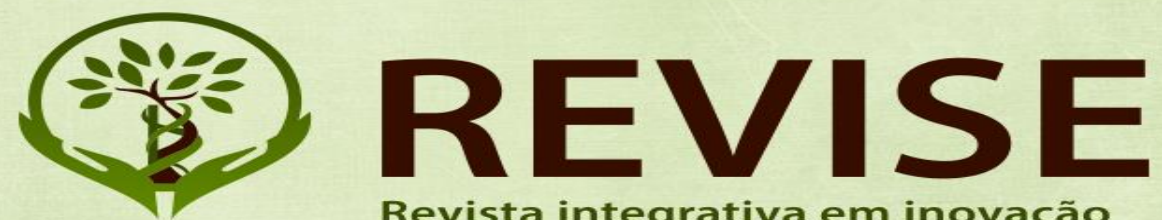

Revista integrativa em inovação tecnológica nas ciências da saúde

ISSN: $2179-6572$

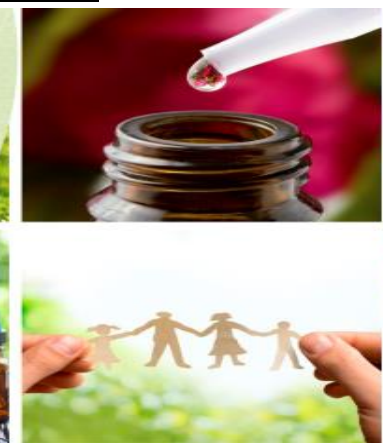

\section{INTRODUÇÃO}

$\mathrm{O}$ atual debate se concentrou nas várias terapias de tratamentos fisioterapêuticos na água (hidroterapia). Valoriza-se o resgate das práticas tradicionais de tratamento, sem ser radical no que se refere aos avanços da medicina convencional ou moderna. $\mathrm{O}$ objetivo é de promover a saúde de maneira mais ampla. A ideia é não ter um enfoque apenas numa única doença, mas olhar para o corpo humano como um todo e tentando combater as doenças na íntegra.

A hidroterapia é uma modalidade terapêutica que o fisioterapeuta dispõe para reabilitar seus pacientes, nesta faz-se o uso do meio físico água. A utilização da água para tratamento e cura de doenças é algo comum aos homens, sendo que a primeira referência a este uso remete a antiguidade clássicas e povos antigos como egípcios, gregos e romanos. Entre os ocidentais este uso pautado em estudos científicos só ocorreu no início do século XX e perdura até os dias atuais. A água como meio terapêutico é entendida tanto na medicina tradicional quanto permeando os conhecimentos dos nossos ancestrais. Assim, faz parte de rituais místicos de cura, tanto nas culturas indígenas, africanas e demais povos que, com crenças e culturas diversas, recorrem a água para extrair benefícios.

São diversos os efeitos fisiológicos da imersão do corpo na água, dentre os quais podem ser citados os efeitos térmicos, relativos ao relaxamento muscular, alívio da dor, melhora na mobilidade articular. Tem-se ainda os efeitos óptico, químico e mecânico, este associado a redução de edemas, ganho de força muscular, melhora na amplitude de movimento e reabilitação de equilíbrio e propriocepção. Este recurso possui algumas indicações como para ganho de força, melhora na marcha, alongamento e reabilitações específicas nos campos da ortopedia, traumatologia, pediatria, neurologia, obstetrícia e outros.

Porém, mesmo com tantos benefícios e possibilidades, existem contraindicações absolutas e relativas, dentre as quais podem ser citadas, queimaduras, feridas, incontinência fecal e urinária, cardiopatias descompensadas e patologias renais 

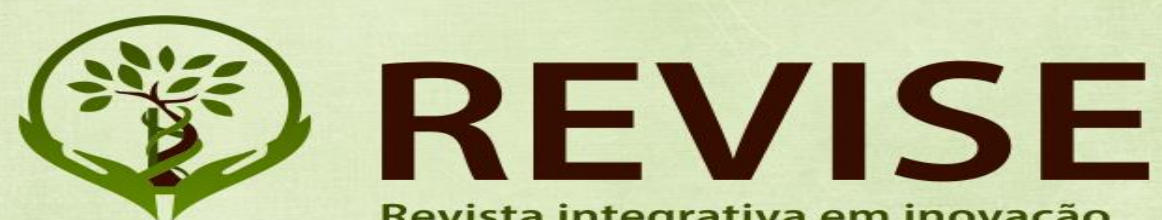

Revista integrativa em inovação tecnológica nas ciências da saúde

ISSN: $2179-6572$

descompensadas. Enfim, as possibilidades de uso da hidroterapia são diversas, cabendo ao profissional uma avaliação detalhada para uma devida identificação das necessidades do paciente a fim de traçar condutas de intervenção eficazes.

\section{Discurso do palestrante:}

Jaqueline costa

Gostaria de agradecer o convite. Bom dia a todos, meu nome é Jaqueline Costa. Diante da última apresentação, tenho o desafio de tentar direcionar " a sardinha pra minha brasa" da prática terapêutica complementar à fisioterapia. E a gente vem falar de medicina tradicional, como também da medicina convencional na prevenção, reabilitação. Então, eu vou tentar trazer um pouquinho o que a fisioterapia pode trazer no sentido da saúde, dentro da integralidade que é tão tamanha, tão vasta e como o conhecimento é importante, valioso porque ele ajuda que a gente abra os horizontes para integrar conhecimento entre áreas diferentes.

$\mathrm{Na}$ verdade, quando a gente busca trabalhar a saúde, podemos focar como profissional na saúde para o outro, porque a gente trabalha com pessoas, com vidas. No senso comum busca-se a saúde a partir do melhor profissional, o mais indicado. Então quando o profissional de saúde somente ministra medicação, intervenção cirúrgica, se esquece que do outro lado existe um ser. Esse ser dentro do que já ouvimos aqui hoje é muito mais que um corpo físico, independente de crenças religiosas, independente da gente aceitar. A gente não pode negar o que existe. A gente não é só um corpo físico que vai ser manipulado, receber um tratamento, num processo frio. Somos muito mais do que isso.

A equipe multidisciplinar, médico, fisioterapeuta, enfermeiro, psicólogo, os mentores espirituais, enfim, seja quem esteja próximo vai ter sempre um papel muito relevante. Eu trago hoje a fisioterapia com esse enfoque. Fui convidada a falar sobre a hidroterapia e dentro do contexto; ao assistir as outras palestras no congresso, fui mudando um pouco do que era a proposta original para a conferência.

Hidroterapia. Revista Revise, vol 3, $n^{\circ}$ Fluxo Contínuo, p.87 a 98. 

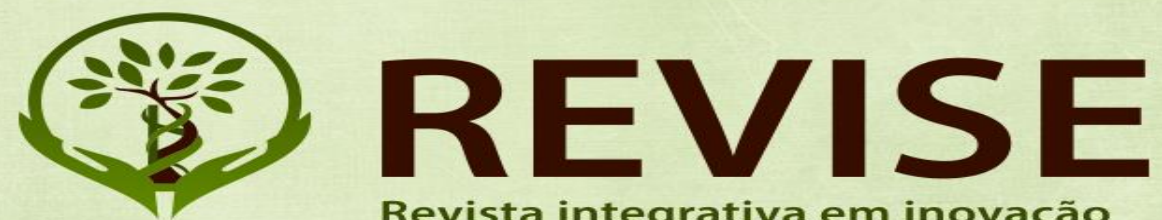

Revista integrativa em inovação tecnológica nas ciências da saúde

ISSN: $2179-6572$

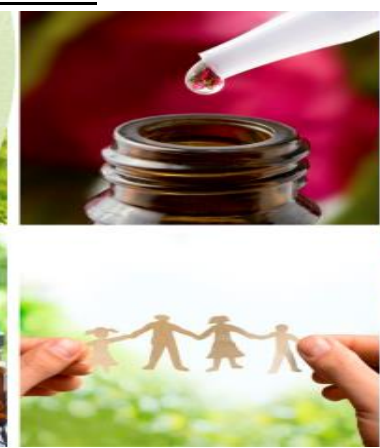

Hoje se utiliza a hidroterapia intensiva de forma alternativa, como também complementar, no sentido de que a sociedade tem uma gama muito grande de modalidades terapêuticas para reabilitação; a hidroterapia pode ser a escolha inicial ou coadjuvante complementar. Então, a gente dispõe dessa técnica hoje também. $O$ professor Júlio como mediador da conferência, descreveu a fisioterapia aquática, como participante do serviço.

A hidroterapia, é um dos recursos, que a fisioterapia dispõe e as diversas áreas dispõe, desde a antiguidade, desde as civilizações mais remotas. O termo grego "hidra" significa água e "terapia", cura, já remete ao passado de modalidade terapêutica muito antigo. O recurso físico água foi utilizado por muitas civilizações. Até o momento não foi possível precisar o ano em que se usou pela primeira a água como modalidade terapêutica. Os primeiros relatos são de cerca de 2000, 2500 anos A.C., lá nas civilizações indianas, com a utilização da água como recurso terapêtico para tratamento de doenças e como banhos de contraste.

Caminhando um pouquinho mais, na medicina, Hipócrates, em 460, 395 AC, ele trazia o recurso uso da terapia aquática, como forma terapêutica, no tratamento de doenças, com banhos de contraste, a utilização do contraste da água quente e fria, um recurso que nos remete ao momento intrauterino. Hoje ainda utiliza esses banhos de contrastes. Nos achados arqueológicos dos egípcios se encontra resquícios de utilização, convencional da água como higiene, banho, alimentação, mas também para ginástica, atividade esportiva, como também terapia.

No ocidente, os romanos já traziam a água como uma utilização terapêutica muito difundida entre as civilizações. E aí, a gente vem para um pouquinho mais próximo de nós, idade média, moderna, contemporânea, na Europa. A Europa, na verdade, foi a precursora na busca científica. O conhecimento abre portas; quando a gente atrela esse conhecimento em diversas subáreas, o conhecimento dos nossos ancestrais, os conhecimentos pretéritos ao conhecimento científico, a gente consegue dar um respaldo muito maior. A Europa inicia isso com os estudos científicos da

Hidroterapia. Revista Revise, vol 3, $n^{\circ}$ Fluxo Contínuo, p.87 a 98. 

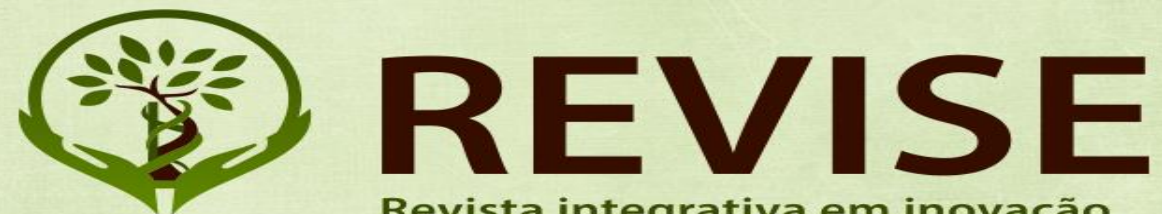

Revista integrativa em inovação tecnológica nas ciências da saúde

ISSN: 2179-6572

utilização da água como um método terapêutico, com os estudos do médico inglês Jhon Flayer, em 1697. o cientista começa a dar um caráter científico a essa terapia, que inicialmente era muito mística. Até o tempo de Flayer não se sabia o porquê dava o resultado, o cientista começa a fundamentar este estudo, fundamentar os usos através de estudos da época. Antropologicamente, um camponês na Silésia começou a desenvolver os primeiros centros de usos da água como exercício físico, mas não se sabe quem foi.

Daí a gente atrela o conhecimento popular, passado de geração em geração, com o conhecimento científico desenvolvido em centros de pesquisa distintos. Na América, infelizmente, a gente começa a despertar um pouco mais tarde na utilização da hidroterapia como recurso terapêutico. Somente no início do séc. XX essa modalidade começa a ser difundida pela América; sendo que o primeiro centro de estudos foi em Boston, nos EUA, em 1903, em que se estudava a utilização da água como método terapêutico. Com os estudos começou a ser difundida por toda a América. As propriedades terapêuticas da água, são difundidas por todas as culturas.

Eu costumo brincar inclusive com alguns pacientes:

- A hidroterapia tem mil e uma utilidades! [parafraseando com a massificante propaganda do Bombril]

Com esse único recurso, um único momento, o profissional consegue diversos efeitos físicos, emocionais, psicológicos, conciliatórios, integrativos. A principal propriedade da utilização da hidroterapia como tratamento, como modalidade, recursos que dispomos, é justamente a possibilidade de em um único momento termos várias possibilidades. Como primeiro efeito da hidroterapia, temos o efeito térmico, relacionado com as questões da termodinâmica, com a movimentação das moléculas da água. Então somente o fato de emergir o indivíduo dentro da água aquecida, o profissional já traz para ele uma série de repercussões positivas, independente da patologia que esse paciente traga.

Hidroterapia. Revista Revise, vol 3, nº Fluxo Contínuo, p.87 a 98. 

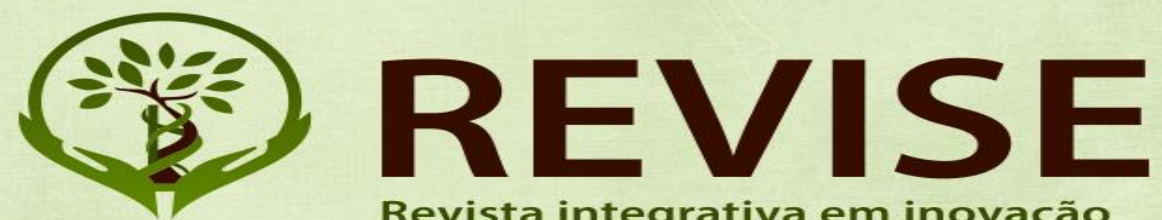

Revista integrativa em inovação tecnológica nas ciências da saúde

ISSN: $2179-6572$

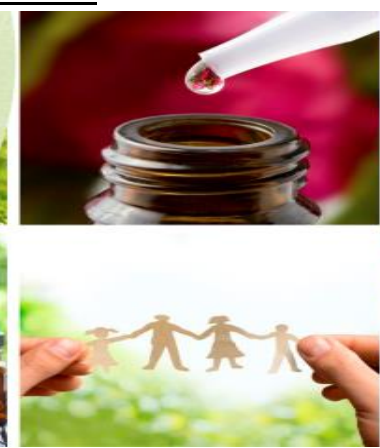

O paciente se sente um meio confortante para o tratamento acolhido, bem recebido pelo fato de o profissional colocar o mesmo paciente numa termodinâmica do efeito térmico entre 32 , a $34^{\circ} \mathrm{C}$ numa piscina terapêutica. A temperatura remete o paciente ao ambiente acolhedor da mãe na gestação, ambiente que já conhece pelas questões evolutivas da espécie: o meio aquático intrauterino por 9 meses. O paciente consegue o relaxamento muscular de imediato, pela temperatura mais elevada; alívio da dor, porque se consegue relaxar esse músculo que está tenso, que traz uma carga; facilitação no ganho da amplitude do movimento, você diminui a dor, melhora mobilidade, melhora independência daquele paciente; e você consegue um incremento, no quadro global, então diminui as limitações do paciente e permite que ele consiga avançar.

Temos o efeito óptico, ao trabalhar com a questão perceptiva do paciente; melhora a marcha dele; auxilia o ganho prospectivo, e uma melhor a mobilidade. Só esse efeito, mais uma vez só o fato de estar dentro da piscina, já consegue um grande avanço na sua condição inicial e na quantidade de efeitos mecânicos pela hidroterapia. Apenas com a imersão, por si só já colabora, contribui na reabilitação como tratamento, pois a água tem o poder de tratar mecanicamente pelas suas propriedades físicas, dentre elas densidade específica, gravidade específica, flutuação e pressão hidrostática, de uma forma geral. Com ela temos a redução de edema, se pensarmos que ao entrarmos na piscina, onde há uma diferença de altura, de uma movimentação já vai gerar uma diferença de fluxo sanguíneo, a gente vai conseguir melhorar esse edema, agente melhor ao fluxo sanguíneo. Dos efeitos associados conseguimos uma grande amplitude de movimento, vamos conseguir movimentos conciliados a movimentação, melhora da força muscular, prospecção, coordenação, equilíbrio. Então observamos que uma única modalidade terapêutica e um meio físico de tratamento possuem uma tamanha repercussão.

Outros efeitos menos mecânicos são mais primordiais, porque se a cabeça não está bem, não funciona o restante. Então, os efeitos fisiológicos e psicológico que

Hidroterapia. Revista Revise, vol 3, nº Fluxo Contínuo, p.87 a 98. 

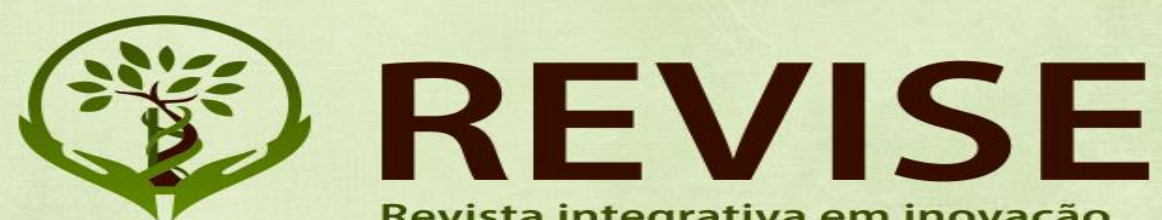

Revista integrativa em inovação tecnológica nas ciências da saúde

ISSN: 2179-6572

vamos observar com a utilização da hidroterapia, eles são tamanhos, talvez eu diria que são os mais benéficos de uma forma geral. Vamos para a interação social. Muitas vezes aquele paciente que está em casa, isolado, com limitação física e que consegue sair naquele momento e ir para uma modalidade dessa terapia; um paciente que sai do seu isolamento, do seu contexto de adoecimento, ele consegue interagir, ele consegue alcançar, consegue se direcionar novas alternativas para o tratamento.

É um incremento maior, com redução de estresse e ansiedade, uma intensificação positiva direcionada às emoções, liberação de endorfina, adrenalina, interação social, o riso, como a gente vem falando da terapia do riso. Então o fato de ter um paciente junto com outro dentro de uma mesma piscina aquecida para uma terapia ajuda com que eles: conversem, interajam, dividam suas angústias, suas posições pessoais e muitas vezes isso é um incremento muito grande. Daí melhora a autoestima, o incentivo do trabalho em grupo, a facilidade do aprendizado. Muitas vezes o paciente é um paciente que tem uma condição limitante muito grande, que tem que reaprender a andar, reaprender a se reequilibrar de pé. Então no contexto de grupo, onde é abraçado, acolhido, incentivado, hoje muitas vezes ele consegue fazer coisas que fora da água não consegue, então ele consegue adquirir esse aprendizado muito mais rápido e fácil e consegue um incremento nas suas condições de saúde muito maior.

A hidroterapia hoje é utilizada em todas as áreas na medicina com algumas limitações específicas, mas que de uma forma geral pode utilizar de uma maneira bem abrangente. Temos a ortopedia, pediatria, a patologia, reabilitação esportiva. De uma forma geral é uma grande maioria das pessoas que buscam na hidroterapia esse tipo de reabilitação. É mais comum, frequente, o acesso a informação de que essas especialidades podem ser tratadas na piscina é muito mais comum, muito mais presente.

A gente tem a utilização de instrumento e materiais, como esteira, jumper, vários objetos que podemos utilizar dentro da água como utilizaria fora, com grandes

Hidroterapia. Revista Revise, vol 3, $n^{\circ}$ Fluxo Contínuo, p.87 a 98. 

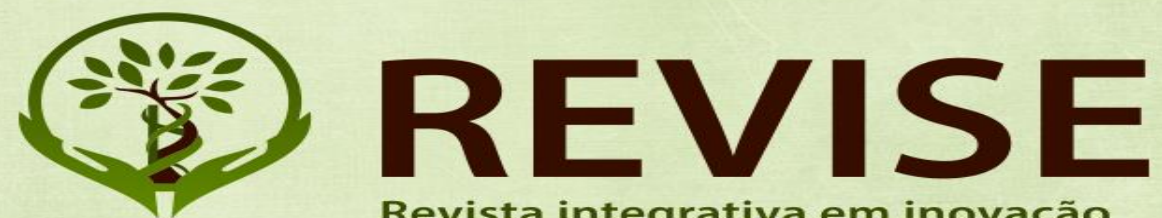

Revista integrativa em inovação tecnológica nas ciências da saúde

ISSN: $2179-6572$

benefícios, a gente usa de uma forma muito mais precoce no processo de tratamento do que a gente utilizaria fora da piscina. Usamos de uma forma muito mais fácil e com menor impacto articular, sem dor, de uma forma mais lúdica, de forma que atrai o paciente para o tratamento e faz com que ele faça sem abandono, com continuidade. Há outra coisa importante, o trabalho pode ser tanto de forma social na díade terapeuta-paciente, como em grupo de terapeuta-pacientes. No trabalho em grupo podemos reunir idades diversas, mas com as mesmas necessidades, reunir patologias diversas, mas com as mesmas necessidades, fazendo com que o tratamento seja mais interessante. Temos a hidroterapia na reabilitação neurológica, tanto de crianças quanto adultos, tanto de forma individual como grupal, de acordo com o quadro clínico, as necessidades e as formas possíveis de intervenção hidroterápica. Como a hidroterapia pode dar um respaldo e um impacto positivo para aquela terapia?

Uma área que eu acho incrível de reabilitação, ginecologia obstetrícia, com a interação do fisioterapeuta com a paciente gestante ou/com com dispareunia, uma dor na região de órgão genital. Nesse momento da gestação é muito importante o trabalho em grupo de apoio: a gestante no trabalho com o fisioterapeuta, o trabalho da gestante com o pai, com o parceiro, com o companheiro ou companheira. Com a interação no momento da hidroterapia, como também a disponibilidade do recurso terapêtico água - minimiza aquelas condições fisiológicas que a gente sabe que acompanha a gestação que causam dor. Com a hidroterapia é possível diminuir esse quadro de dor, aumentar a condição de qualidade de vida, proporcionar uma melhora na saúde, e a passagem por esse período de estado gestacional muito mais confortável. Mesmo nos casos de gravidez com acompanhamento de pré-natal, é possível encontrar alguns com os conceitos do senso comum: a reabilitação focada nas questões de equilíbrio, prospecção. O profissional constrói formas de ensino e aprendizagem para trabalhar novos conceitos de reabilitação centrada na pessoa, em seu processo de desenvolvimento.

Hidroterapia. Revista Revise, vol 3, nº Fluxo Contínuo, p.87 a 98. 

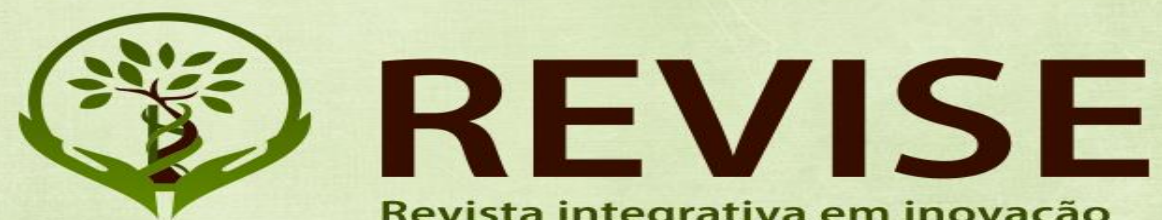

Revista integrativa em inovação tecnológica nas ciências da saúde

ISSN: $2179-6572$
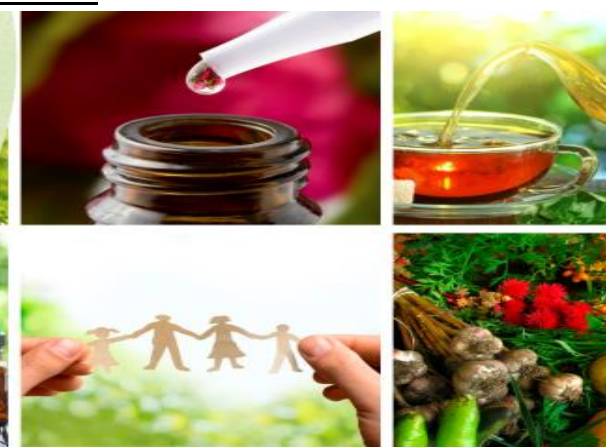

A reabilitação cardiovascular é uma área muito delicada que, muitas vezes, as pessoas acreditam não ser possível atividade física aquática. A depender do quadro de patologia na sua trajetória de vida, do momento em que o paciente se encontra, o profissional pode trabalhar na água também. Pode-se começar a reabilitação na piscina com o paciente estável, indicado para uma atividade física. Com a reabilitação hidroterápica precoce é provável que o paciente saia do leito mais cedo, como também melhore sua autoestima. É possível intensificar o tratamento, dentro de uma análise bem detalhada. Na reabilitação cardiovascular, o paciente está contra indicado nos casos de cardiopatia descompensada, ou seja, qualquer quadro clínico em que haja uma descompensação, o paciente não esteja estável, sem acompanhamento médico, sem indicação para o tratamento fisioterápico aquático, inapto para a atividade física. Outros casos de contra indicação são situações em que os pacientes estão com a incontinência fecal urinária, como também com queimaduras, processos de feridas, de lesões de continuidade na pele.

A hidroterapia é uma modalidade terapêutica na qual o fisioterapeuta lança mão das atividades na água como ferramenta para seu trabalho. Essa modalidade faz uso de várias técnicas, umas mais conhecidas do público que outras. Umas estão mais divulgadas, pois demonstra a gama de possibilidades que temos nesse recurso. A gente traz a técnica da hidropilates, a gente já ouviu falar em pilates convencional, em solo, em aparelhos, mas a gente pode trazer para o hidropilates, a utilização de vários objetos, e vários utensílios que a gente usa fora da piscina, que a gente pode utilizar dentro, e utilizar os mesmos mecanismos de ativação do power house, força, musculatura abdominal, trabalho respiratório, tudo isso a gente pode fazer dentro da piscina em grupo também, ou individual, de uma forma geral essas atividades são desenvolvidas em grupos pois são atividades mais lúdicas com pacientes que tem uma rigidez muito maior, mais que prepara e condiciona o paciente de uma maneira mais rápida e mais divertida, a gente tem a técnica dos anéis que são utilizados flutuadores como a gente observa aqui, pescoço, tronco, pernas, e o terapeuta ele trabalha com o

Hidroterapia. Revista Revise, vol 3, $n^{\circ}$ Fluxo Contínuo, p.87 a 98. 

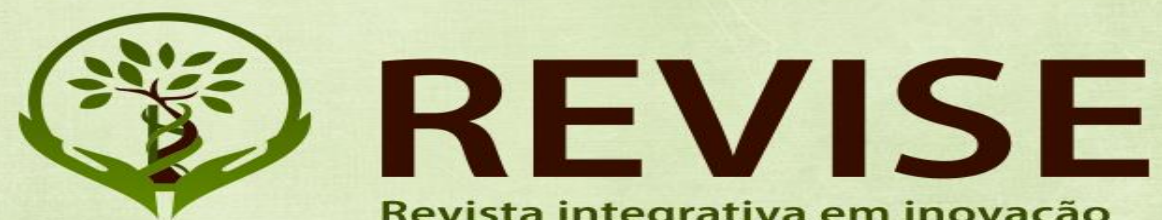

Revista integrativa em inovação tecnológica nas ciências da saúde

ISSN: $2179-6572$

paciente exclusivamente na posição horizontal no sentido de trabalhar em mobilidade, relaxamento muscular, alongamento, ganho de força, enfim, a gente tem uma possibilidade muito grande com essa técnica, uma técnica que é altamente difundida e que hoje já é utilizada em larga escala.

Tem uma técnica inicialmente desenvolvida para o ensino da hidroterapia, utilizando as potencialidades do participante, o que esse paciente consegue, qual o seu interesse. Sem focar nas suas limitações, na deficiência do paciente. Então o paciente se adéqua às faixas de possibilidades, e a partir disso aí, evolui de grupo a grupo de acordo com a sua possibilidade. O trabalho é em grupo de interação social, de elevação da autoestima, de readaptação desse indivíduo que é muito gratificante. $O$ profissional trabalha com faixas etárias diversas, com também com mulheres, homens, crianças. O profissional incentiva o paciente cada vez mais a conseguir um incremento em sua condição de saúde.

A gente tem uma outra técnica, em que se trabalha na díade fisioterapeutapaciente, a dança aquática. Nessa técnica o paciente pode conseguir os movimentos serpenteados, como também lento, no intuito de dar mais mobilidade, relaxamento muscular, diminuição da ansiedade, do quadro de estresse. O profissional pode conseguir que esse paciente tenha uma mobilidade, um alongamento, uma fluidez no corpo muito maior. A técnica é utilizada por todas as faixas etárias e quadros clínicos, de acordo com a necessidade e a possibilidade desse paciente.

É um desafio pensar na hidroterapia hoje: é uma técnica de custo elevado para utilização, não só de quem frequenta a hidroterapia, mas também para quem abre uma clínica com essa modalidade. É uma modalidade bastante gratificante com recursos diversos. A gente tem como fazer uma intervenção muito precoce, tem como fazer com que o paciente se sinta apto a trabalhar, a se locomover muito mais rápido. A interação social desses pacientes é muito importante, pois a gente consegue o retorno na reabilitação, como também da qualidade de vida: É muito mais que uma reabilitação física, é uma reabilitação emocional, social, e é algo que é bastante gratificante. Alguns

Hidroterapia. Revista Revise, vol 3, $n^{\circ}$ Fluxo Contínuo, p.87 a 98. 

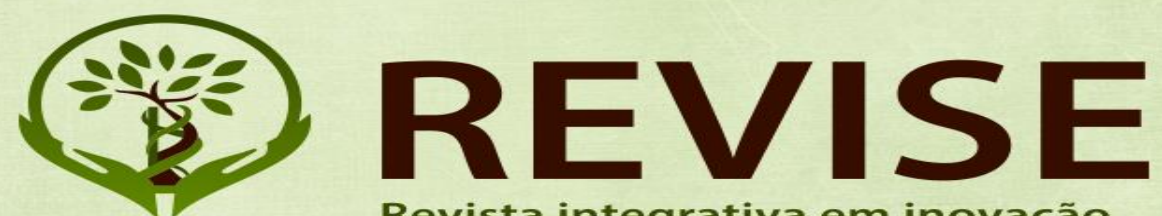

Revista integrativa em inovação tecnológica nas ciências da saúde

ISSN: $2179-6572$

centros de estudos se disseminam a hidroterapia pelo país, com o desenvolvimento de técnicas, como também de estudos. É uma técnica difundida na universidade, por gente pensa em saúde, na reabilitação, na prevenção. Eu queria agradecer o convite mais uma vez, e colocar a disposição para possíveis questionamentos. Obrigada.

\section{Comentários dos congressistas}

"Este debate se concentrou nas várias terapias incluindo tratamentos fisioterapêuticos na água (hidroterapia). A professora Jaqueline Tosta de Almada Santana tratou do tema da Hidroterapia. Os membros da Associação dos Amigos do Parque Nacional de Brasília/Brasil realizam a hidroterapia todos os dias as 05 horas pela manhã na modalidade de Medicina Tradicional com água mineral. Todo dia de manhã pessoas acordam cedo para fazer natação na água mineral. Na água minera professora, nós não temos instrutor de natação orientando os matadores pela manhã. Os nadadores se auto orientam de acordo com sua experiência. O parque público com água limpa, piscinas naturais desde 1960; e todo dia tem um grupo de visitantes, de idosos a jovens, que utilizam o parque para fazer terapia de todas as formas que vocês pensarem. E isso é muito interessante, a gente observar que na água, a gente também pode fazer e ter um nível de tratamento muito melhor.

No Espírito Santo temos um programa muito legal com a prefeitura, a universidade e com profissionais de práticas integrativas para que quem precisa de promoção, prevenção e recuperação da saúde no pós-operatório. Todo o processo do pós-operatório com a fisioterapia, é feito dentro do parque e nos polos de saúde nas praias. Na parceria da Universidade Federal do Espírito Santo com modalidade de práticas integrativas, as pessoas têm a prática de Yoga e Tai Chi Chuan. As pessoas chegam de manhã, como também os profissionais: o médico, enfermeiro, e o profissional de práticas integrativas. Eles aferem a pressão arterial para orientar a velocidade da caminhada pela manhã: "Olha, você pode aumentar o seu passo hoje na

Hidroterapia. Revista Revise, vol 3, nº Fluxo Contínuo, p.87 a 98. 

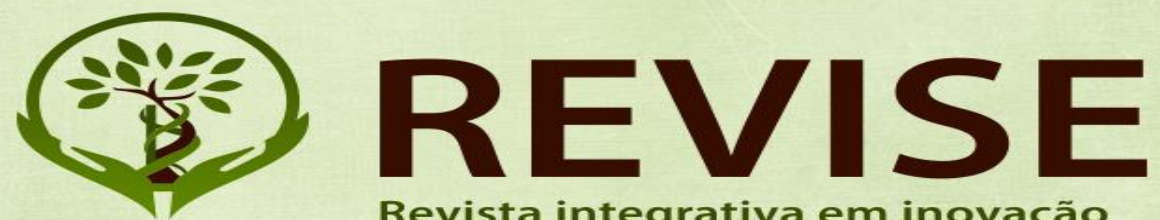

Revista integrativa em inovação tecnológica nas ciências da saúde

ISSN: $2179-6572$

caminhada, na corrida”; "Olha, hoje estou vendo que sua pressão está um pouco diferenciada, você vai mais leve hoje!" E aí, durante o ano você tem sua curva, como ta indo sua pressão arterial e eles te orientam o que fazer e a coisa vai caminhando. E o nível de recuperação é muito melhor do que a recuperação feita só dentro dos laboratórios e das clínicas. A professora encontrou resultados de pesquisas interessantes. Eu posso comprovar que é muito bom, pois fui paciente nas massagens e hidroterapia. 